ISSUES AND INNOVATIONS IN NURSING PRACTICE

\title{
Abuse-related post-traumatic stress during the childbearing year
}

\author{
Julia S. Seng PhD CNM \\ Assistant Research Scientist, School of Nursing; and Research Investigator, Department of Obstetrics and Gynecology, \\ University of Michigan, Ann Arbor, Michigan, USA \\ Lisa Kane Low PhD CNM FACNM \\ Assistant Research Scientist, School of Nursing; and Lecturer, Women's Studies Program, University of Michigan, Ann Arbor, \\ Michigan, USA \\ Kathleen J. H. Sparbel MS FNP \\ Clinical Instructor, University of Illinois at Chicago, Quad Cities Regional Program, Moline, Illinois, USA \\ Cheryl Killion PhD RN \\ Director, Center for Minority Family Health, Hampton University, Hampton, Virginia, USA
}

Received for publication 22 November 2002

Accepted for publication 12 November 2003

\author{
Correspondence: \\ Julia Seng, \\ School of Nursing, \\ University of Michigan, \\ 400 N. Ingalls, \\ Ann Arbor, \\ MI 48109-0482, \\ USA. \\ E-mail: jseng@umich.edu
}

SENG J.S., LOW L.K., SPARBEL K.J.H. \& KILLION C. (2004) Journal of Advanced Nursing 46(6), 604-613

Abuse-related post-traumatic stress during the childbearing year

Background. Women with abuse-related post-traumatic stress who are pregnant experience symptoms that nurses and midwives may not recognize or know how to respond to.

Aim. The purpose of this article is to increase familiarity with the post-traumatic stress disorder diagnostic framework by illustrating the symptom categories and associated features with women's descriptions of the symptoms from qualitative interviews.

Methods. A secondary analysis was performed with data from a qualitative interview study of the maternity care experiences of 15 American women who had abuse-related post-traumatic stress during pregnancy. Content analysis was used to extract all participant statements describing how post-traumatic stress disorder symptoms and associated features manifested in pregnancy. These were then juxtaposed with the post-traumatic stress disorder diagnostic framework.

Results. Participants' interviews included a range of descriptions of the intrusive re-experiencing, avoidance and numbing, and hyperarousal core symptoms of posttraumatic stress disorder, as well as associated psychological features such as somatization, dissociation and interpersonal sensitivity, and associated behavioural features such as substance abuse, disordered eating, high-risk sexual behaviours, suicidality, and revictimization.

Conclusions. Limitations of this study include that it is a secondary analysis, using a small North American sample, and focusing only on abuse-related post-traumatic stress disorder. Descriptive information from this qualitative study may bridge the gaps between psychiatric technical language, women's subjective experiences, and clinicians' perceptions of a woman's post-traumatic stress reactions. 
Keywords: post-traumatic stress disorder, violence against women, abuse, pregnancy, childbirth, midwifery

\section{Background}

The prevalence of violence against girls and women is very high globally. It is important to offer interventions to stop violence and also to treat its sequelae within the context of women's health care [World Health Organization (WHO) 2002, Heise 1994]. The mandate to respond to disclosure of violence occurring around the time of pregnancy is clear (Gazmararian et al. 2000, McFarlane et al. 2002 Petersen et al. 1997). Clinical literature has also encouraged caregivers to screen for past abuse, especially childhood sexual abuse [American College of Obstetricians and Gynecologists (ACOG) 2001, Bohn \& Holz 1996], because abuse trauma is associated with numerous physical and psychological sequelae. Maternity care represents an important opportunity for intervention because health care providers have a prolonged relationship with women that includes attention to normative emotional and developmental needs as they prepare for motherhood (Keirse et al. 2000). This 9-month relationship could facilitate disclosure and supportive interventions related to violence and abuse. However, many of the long-term negative effects of abuse trauma are considered to be mental health problems, and the US health care system is a segmented one in which mental health services are usually accessed separately from maternity care services. This segregated approach results in gaps in the training and knowledge base of maternity care professionals, such that they may not recognize or know how to respond to abuse trauma and its effects in their pregnant clients.

Some obstetric and midwifery literature describes how the post-traumatic stress disorder (PTSD) conceptualization is useful for understanding abuse-related symptoms and distress and for organizing assessment and therapeutic responses (ACOG 2001, Bohn \& Holz 1996, Seng \& Hassinger 1998, Seng 2002, Simkin \& Ancheta 1999). The PTSD conceptualization [American Psychiatric Association (APA) 1994, WHO 1978] is generally valid across populations, with some variations according to the person's culture (Marsella et al. 1996) and the nature of the trauma (Herman 1992, Sironi 1999). Recent research also found that PTSD was associated with physical complications of pregnancy that were congruent with prior published clinical observations of pregnant sexual abuse survivors and consistent with biological theories about PTSD (Seng et al. 2001). Since effective treatments for PTSD exist (Foa et al. 2000, Herman 1992, Sironi 1999), it may be useful for maternity care providers to frame their responses to women struggling with trauma-related symptoms and concerns by assessing for PTSD.

While many maternity care providers can intellectually appreciate the potential for previous abuse to affect the current experience of pregnancy, responding to abuserelated post-traumatic stress in actual maternity care practice can be daunting when clinical presentations of the symptoms are diverse, complex, and potentially misidentified (ACOG 2001, Bohn \& Holz 1996, Seng \& Hassinger 1998). Furthermore, psychiatric writing about abuse sequelae and post-traumatic stress phenomena often uses psychological language that may not be descriptive enough to facilitate recognition of these symptoms for those outside the mental health professions.

\section{The study}

\section{Aims}

The aim of this paper is to bridge the gaps between what maternity care providers are seeing and responding to in clinical encounters, what trauma-affected women experience subjectively, and PTSD mental health diagnostic frameworks and language (APA 1994, WHO 1978).

\section{Design}

The paper reports the results of a secondary analysis of qualitative interviews from a study of what women with abuse-related post-traumatic stress during their childbearing year wanted from maternity care providers. Findings from this content analysis illustrate the PTSD diagnostic criteria and associated features (APA 1994) using the words of abuse survivors talking about their experiences in maternity care.

\section{Original interview study}

\section{Design}

An initial qualitative interview study was conducted in 20002001 (Seng et al. 2002) to answer the research question, 'What do pregnant women who have experienced abuserelated post-traumatic stress during their childbearing year want from maternity care providers?' This original study used a narrative approach because this has been found to be 
particularly valuable when the goal is to organize, interpret, and explain a patient's illness. Narratives also provide a way to revealing experiences that are too painful or taboo to discuss in a straightforward manner (Eggly 2002). In the process of explaining what they wanted from maternity care providers, the interviewees described their inner experiences of how past abuse and post-traumatic stress phenomena affected them during the childbearing year. These descriptions are the focus of this secondary content analysis of the qualitative interviews.

\section{Participants}

Participants for the study were recruited by flyers and snowball techniques. Criteria for participation included any adult woman who self-identified as having had a history of child sexual abuse and post-traumatic stress that affected her childbearing experience. Fifteen women volunteered and took part in interviews that lasted between 45 minutes and 2 hours. Ethical and safety recommendations for research on violence against women [Parker \& Ulrich 1990, Global Programme on Evidence for Health Policy (GPE/99.2) 2002] were followed.

\section{Interviews}

A semi-structured interview process was used, starting with an orienting '2-minute version' of her childbearing story, followed by in-depth narrating of her childbearing experience with the trauma history and post-traumatic stress elements that were salient to the woman's story. At the conclusion of the interview, the participant was asked to provide 'bullet points' with the 'take home messages' about what she wanted from maternity care providers. This served to validate that the participant's most crucial points had been understood by the interviewer and were conveyed in her own words. The bullet points were extracted from the transcript and used as an audit tool to assure rigour in the analysis phase of the study.

\section{Data analysis}

The interviews were taped and transcribed verbatim. In keeping with a narrative approach, the unit of analysis for the main research question was the story as a whole (Reissman 1993). Two of the investigators conducted the initial analysis which involved multiple readings of all 15 interviews and summarizing the narratives into multiple matrices so that commonalities and patterns could be seen. The other two then verified that the results followed closely from the interview transcripts, and the audit was done to assure that the information in each woman's 'bullet point messages' had been addressed in the findings.

\section{Secondary data analysis}

During the close readings of the transcripts, it became evident that the descriptions of post-traumatic stress phenomena were rich and detailed. A secondary content analysis was then conducted using a qualitative content analysis approach (Morgan 1993). This method was chosen because the goal was to apply an established, pre-existing taxonomy or coding scheme (the PTSD diagnostic criteria) to 'the manifest content of communication', in this case, the content of the narratives (Berelson 1952, p. 18). For this secondary analysis, each transcript was re-read and each instance when a narrator alluded to or described how PTSD manifested for her was marked. There was a high level of agreement about which utterances constituted description of post-traumatic stress. Content analysis methodology was applied by juxtaposing these descriptions with elements of the APA's (1994) PTSD diagnostic framework of core symptoms and associated features (summarized in Table 1). Pseudonyms are used in reporting the data.

\section{Results}

The 15 participants were White, Hispanic, and African American women from rural, small town, and urban locations in the Midwestern United States of America (USA), some of whom also had experienced adult sexual assault and intimate partner violence in addition to child abuse. Table 2 summarizes demographic and history information. They varied in the extent to which post-traumatic stress symptoms and associated features entered into their childbearing narrative. Several would probably have met full diagnostic criteria for PTSD during the pregnancy. Others experienced only some symptoms during pregnancy, but met diagnostic criteria at other periods in their lifetime. Table 3 depicts the distribution of PTSD core symptoms and associated features among these women, as disclosed in their childbearing stories.

Among these 15 women, the nature of their abuse history, distribution of PTSD manifestations they described, and recovery strategies they used before, during, and after pregnancy represented a wide range of experience. Where the woman was in the longitudinal process of recovering from post-traumatic stress was an important factor in determining how well she could recognize her needs and ask for help with them. From the quotes presented below, it is evident that some were affected by post-traumatic sequelae that made their childbearing high risk. However, even the less symptomatic women judged post-traumatic sequelae to be a relevant issue in pregnancy, because they 
Table 1 Summary of post-traumatic stress disorder diagnostic criteria based on the Diagnostic and Statistical Manual of Mental Disorders, 4th edition (APA 1994). Reprinted with permission from the Diagnostic and Statistical Manual of Mental Disorders, (C) 2000 American Psychiatric Association.

Trauma

Criterion A: exposure to a qualifying trauma, one that involved experiencing or witnessing an event involving threat to life or physical integrity and a response of fear, helplessness or horror

Symptoms

Criterion B: intrusive symptoms (at least 1): nightmares, flashbacks, unwanted memories, feeling like the trauma is recurring, intense psychological distress at reminders

Criterion C: avoidance and numbing symptoms (at least 3): avoiding reminders, inability to recall aspects of the trauma, feeling detached or estranged, restricted affect

Criterion D: arousal symptoms (at least 2): irritability or outbursts of anger, hypervigilance, exaggerated startle, difficulty falling or staying asleep, difficulty concentrating

Duration and intensity

Criterion E: duration of the disturbance is $>1$ month

Criterion F: causes clinically significant distress or

Specify if acute (duration $<3$ months) or chronic ( $>3$ months)

Specify if with delayed onset, if onset of symptoms is $>6$ months after trauma

Associated features: guilt about what they had to do to survive; phobic avoidance; self-destructive/impulsive behaviour; dissociative symptoms; somatic complaints; feelings of ineffectiveness, shame, despair, or hopelessness; feeling permanently damaged; a loss of previously sustained beliefs; hostility; social withdrawal; feeling constantly threatened; impaired relationships with others; or a change from the individual's previous personality characteristics

Table 2 Socio-demographic characteristics of the 15 narrators at the time of pregnancy

\begin{tabular}{lr}
\hline Age group & 2 \\
Teen & 10 \\
$20 \mathrm{~s}$ & 3 \\
$30 \mathrm{~s}$ & \\
Ethnicity & 1 \\
$\quad$ Hispanic & 1 \\
African-American & 13 \\
European-American & \\
Marital status & 10 \\
Married & 5 \\
Not married & \\
Trauma history & All \\
Child sexual abuse & 3 \\
Adult sexual assault & 7 \\
Intimate partner abuse & \\
Mental health care before pregnancy & 8 \\
Yes & 7 \\
No & \\
Income level & \\
Poor & 4 \\
Modest & 7 \\
Affluent & 4 \\
\hline
\end{tabular}

were still focused on limiting triggers and achieving posttraumatic growth (Tedeschi et al. 1998). Those who had had psychotherapy had more of a ready vocabulary of posttraumatic stress to use in describing their experiences.

\section{Women's descriptions of post-traumatic stress}

The diagnostic criteria for PTSD were developed in work with combat veterans. Civilian women whose trauma is from interpersonal violence sometimes have equivalent levels of distress and impairment, even without meeting all the criteria (Breslau et al. 1997, Stein et al. 1997), and sometimes their post-traumatic stress includes psychological and behavioural alterations that go beyond the PTSD core symptoms (Roth et al. 1997). The following sections illustrate the core symptoms and associated features with excerpts from the narratives. Writing about the symptoms and illustrating them with quotes in separate paragraphs is useful for the sake of simplicity, but we do not mean to imply that these are discrete, easily categorized phenemena. In reality the symptoms interact with each other in ways that are most coherent when viewed together as a complex dynamic process.

\section{Intrusive re-experiencing}

Intrusive re-experiencing symptoms are a hallmark of PTSD. To meet diagnostic criteria, a person must experience at least one of them: nightmares, flashbacks or the feeling of re-living the trauma, unwanted memories, intense emotional reactions, or intense physical reactions to reminders of the trauma (APA 1994, Herman 1992). Some of the women in this study had little or no memory of childhood abuse prior to pregnancy and were not ready to address post-traumatic stress explicitly at the time, although they were symptomatic. As Sonya 
Table 3 Distribution of PTSD symptoms and associated features in the 15 narratives

\begin{tabular}{|c|c|c|c|c|c|c|c|c|c|}
\hline \multirow[b]{2}{*}{$\begin{array}{l}\text { Participant } \\
\text { pseudonym }\end{array}$} & \multicolumn{3}{|c|}{ PTSD symptoms } & \multicolumn{6}{|c|}{ Associated features } \\
\hline & Intrusive & Avoidance & Arousal & Somatization & Dissociation & $\begin{array}{l}\text { Interpersonal } \\
\text { sensitivity }\end{array}$ & $\begin{array}{l}\text { Substance } \\
\text { use or eating } \\
\text { disorder }\end{array}$ & $\begin{array}{l}\text { Risk or } \\
\text { self-harm } \\
\text { behaviours }\end{array}$ & Revictimization \\
\hline Sonya & + & + & + & + & + & + & & & \\
\hline Pam & & + & + & + & + & + & & + & \\
\hline Kate & & & & & & + & & + & + \\
\hline Kristin & & & & & & + & & & \\
\hline Karen & + & + & & & & + & & + & + \\
\hline Elizabeth & + & + & & & + & + & & & \\
\hline Julie & + & + & + & & + & + & + & + & + \\
\hline Emily & + & + & + & & & & & + & + \\
\hline Claire & + & + & + & + & + & + & + & & \\
\hline Rachel & + & & & & & & & & \\
\hline Sara & + & + & + & & & & + & & + \\
\hline Ellen & + & + & & & + & + & & + & + \\
\hline Susan & & & & & & + & + & + & + \\
\hline Leslie & & & & & & & + & & + \\
\hline Terry & & & & & + & & + & + & + \\
\hline
\end{tabular}

described it, 'I had nightmares and things and, you know, fleeting memories. But I was working really hard to keep [the pregnancy and abuse spheres of experience] apart.' Others had vague knowledge that became more complete as intrusive re-experiencing brought greater awareness of their bodily or emotional responses during the abuse. Emily experienced flashbacks for the first time during pregnancy. She described them as physical and affective memories that became particularly distressing during breastfeeding:

...every time [the infant] would latch on to nurse I would just sort of be hit with these uncomfortable...kind of nauseating...I call them flashbacks, but it's not like I'm reliving the incident, it's just sort of the physical manifestation of the incident. It's really hard to describe...it just feels awful. I feel like turning into a little black hole and disappearing.

Other participants had had psychotherapy for trauma-related problems prior to pregnancy. Rachel used mastery she had gained previously to keep intrusive symptoms from becoming too distressing when she re-experienced abuse pain during labour contractions. She explained that 'It was peripheral...a little bit of a quick resurface, so to speak... a combination type thing: fear, pain, problems...'

\section{Avoidance and numbing}

Avoidance and numbing characterize the second symptom cluster. To meet diagnostic criteria, a person must experience three of the following: avoiding thoughts and feelings associated with the trauma, avoiding activities, situations, or places that are reminders, having aspects of the event that she cannot recall, losing interest in activities, feeling detached or cut off from others, having decreased ability to experience emotions, or having a foreshortened sense of the future (APA 1994, Herman 1992). Some women in this study used avoidance purposefully, as Sara described: 'I can't watch any [television] shows...no violence against women. I can't watch'. Others have a more chronic emotional numbing such as Karen experienced: 'It was kind of like a piece of clothing, you know...You put on your shoes, you put on your socks, you've been abused, you put on your shirt, you put on your pants...I don't know how to describe it...there was no emotion to it'.

\section{Arousal}

Arousal symptoms, taking the forms of hypervigilance or autonomic hyperarousal, are the third symptom cluster, and a person must have two of these: difficulty falling or staying asleep, irritability or angry outbursts, difficulty concentrating, being overly alert to danger, having an exaggerated startle reflex (APA 1994, Herman 1992). Emily explained:

It just gets exhausting...these flashbacks and stuff...I feel like I'm sitting naked in a room in front of a group of really antagonistic men who are all about to hurt me...that's the best way that I can describe it... and I'm sitting there thinking, 'Oh my god, I've got to protect myself'...I would say powerlessness and vulnerability are the two main feelings, to an overwhelming extent...

Sonya described this sort of hypervigilance in relation to using medication for hyperemesis: 
'I cried for three days before I finally used them [pills] and I was terrified at what they might do. I was very...I don't want anything else in my body'.

Pam's experience of pregnancy involved a strong sense of threat:

I mean, I was in a blind panic throughout the entire pregnancy...I have been in and out of therapy all of my adult life. I am very fearful still, very jumpy, very insecure. I am also unbelievably stubborn. I'm a fighter.

Sara's family was aware of her hyperarousal because:

...when I first moved in with my parents and for about three years, they would wake me up from across the room because I would have such, like I'd come up swinging from sleep.

\section{Sequelae of childhood sexual abuse}

Among people who have survived prolonged or repeated trauma exposures, especially that occurring in childhood, long-term negative effects can go beyond the symptom clusters previously described. Several of the associated features of PTSD have been conceptualized as being part of a disorder of extreme stress or 'Complex PTSD' (Herman 1992). Somatization, dissociation, and interpersonal problems are among the psychological associated features. Substance abuse, disordered eating, high-risk behaviours (including suicidality), and revictimization are behavioural associated features.

\section{Somatization}

As a population, women with histories of abuse present more often to health care providers with somatic complaints that are clinically significant but medically unexplained (APA 1994, Herman 1992). Somatization may play an even more important role in PTSD in some non-Western cultures (Marsella et al. 1996, Sironi 1999) The alternating PTSD phases of intrusive reexperiencing and numbing on top of the chronic autonomic activation corresponds to a wide range of subjective experiences of bodily states. Some of the women interviewed experienced clinically significant symptoms from among the pain, gastrointestinal, genitourinary, sexual, and neurological symptoms that define the somatoform disorders (APA 1994). Others experienced decreased body awareness generally, and found the sensations of pregnancy difficult to tolerate, although the bodily experience of pregnancy was rewarding for others. Sonya considered her persistent hyperemesis to be a coherent and very difficult somatic symptom of PTSD. She explained:

I think I worked very hard during that period to keep the wall up between the two [pregnancy and abuse]...my father was around, and
I still hadn't acknowledged any of that [history of rape]...But, you know, the vomiting and things went to such a huge extreme because he was in my life at that point again, so, whether it was the pregnancy or him...I guess it's hard to know.

Pam, who has fibromyalgia and lupus, said:

I would guess that at least half of the physical distress [of pregnancy] was directly linked to the abuse...It was like my body was taken over by aliens...pregnancy is a sexual experience....and so, once again I was out of control in the sexual experience, and I think that added a very solid chunk of the physical distress.

Claire had the converse difficulty of having always struggled with dissociation, experiencing her body indistinctly. She tells about this difficulty in relation to triage visits for preterm contractions where:

I went in four times, and by about the third time...the abuse stuff had really started to kick up, and I was convinced that I was imagining the whole thing...By the end of it I was convinced that I wasn't even pregnant...you know how denial works.

\section{Dissociation}

Dissociation is a coping mechanism where there is 'a disruption in the usually integrated functions of consciousness, memory, identity, or perception of the environment' (APA 1994, p. 477). This is a sort of altered consciousness that may come into play during an overwhelming trauma when neither fight nor flight is possible, and so a sort of freezing or self-anaesthesizing response occurs (Rothschild 2000). It can then become over-generalized and occur in response to reliving or even mere reminders of the trauma. Dissociation occurs along a continuum from normal, adaptive splitting off of awareness or affect to more comprehensive and problematic forms where the person responds to stressors as though from within an earlier developmental stage or, in the case of dissociative identity disorder, from within a part of themselves that has different personality attributes. Sonya describes the sort of self-anaesthesizing dissociation that was not noticed by her maternity care provider, although it was severe enough that she had to read books to learn about pregnancy because she could not take in any information given during prenatal visits. As she characterized her state, '...just kind of glazed over and drugged is the way it felt'. Julie also tearfully remembered dissociation's function for her during labour saying, 'I was probably being 'out of it'. Terry also describes the childhood cause of this form of coping during her labour, explaining its origins:

...I can only remember [labour up to] a point, and then it just all goes away...And I picked that up from, you know, when my brother used 
to molest me...You know what I would do is I would just close my eyes real tight and just imagine my spirit being lifted up out of my body and sitting on the bed until he was done. Then I would come back into myself. [And in labour] what happened was [the doctor] left and while I was going through labour I just blocked myself out. I blocked myself out through the pain and just took it.

Elizabeth alluded to dissociation where child-like responses occurred: '...you know, you may not be dealing with someone who's acting as an adult here. There is stuff getting triggered...' Although it can at times be helpful to use dissociative coping to get through stress or pain, Julie's tears, the child-like reactions Elizabeth refers to, and Sonya's awareness that she missed important information imply that it does not feel like an optimal way to respond.

\section{Interpersonal sensitivity}

Interpersonal sensitivity is one way to speak of the entire range of problems in relationships that could logically occur for a person who has been abused as a child by a trusted person. For female abuse survivors, those problems range from low self-esteem to self-hatred and self-harm; from relational disturbances including difficulty trusting, to vulnerability to revictimization, to borderline personality disorder; and constricted or uncontrolled affects and behaviour (APA 1994, Herman 1992). The women in this study talked about problems in this category by describing their interactions with others or naming specific behaviours in relationships. Ellen said:

Probably the most important example is what used to happen to me...Some man would be saying inappropriate things to me or something like that, and I would feel really uncomfortable, but I would just block that feeling...instead of just saying to someone 'get lost,' I'd just let them be really inappropriate instead of setting...it was both a boundary issue and also not being in touch with how I felt about things.

Although Claire was happily married to a supportive man, she was still generally triggered by men and negotiated with her nurse-midwife to try to prevent having to cope with any male caregivers; as she told it, 'I said I had real trouble with men and that I didn't want any men in the delivery room...' About the choice to have midwives and a home birth, Pam said:

I don't think that I could have stayed sane through the pregnancy and handed over all aspects of my care to someone else. I don't know about abuse survivors in general, but for me personally, handing over responsibility for something entirely to someone else is miserable.

Problems with relationships also may lead to problems with parenting. For one of these women, child protection services were required. Kate, whose first two children were placed in foster care and eventually adopted, still had custody of her youngest child, but her expectations of the 4 year old were unrealistic and not informed by empathy. She said: 'I want an independent child so I can get things done around the house and do what I want to do. She can take care of herself'.

\section{Substance abuse and disordered eating}

Substance abuse is associated with PTSD and is often considered a form of self-medication for the intense symptoms (Miller \& Guidry 2001). Eating also can become disordered because eating provides physiological soothing or can become dysregulated by efforts to arrive at a body shape that feels safer (Herman 1992, Miller \& Guidry 2001). Some of the women in this study had eating and substance use problems at some point since being abused. Some were already sober prior to pregnancy and others stopped using substances because they were pregnant, but two who had violent partners were addicted to cocaine. Claire said that her sobriety was important to plans for labour pain management because:

I am a recovering alcoholic, so I didn't want to take any [narcotics or sedatives]...At that point I was five years sober, so I didn't want to do any of that.

By contrast, Leslie gave her interview for the study from within a residential drug treatment programme. She was pregnant again, shortly after having had a stillborn infant. She said:

I do have a drug addiction. It was a coping mechanism I used when I was going through [domestic violence]...when I got pregnant with [my son who was stillborn]...[my husband] had already broken my ribs and other things...And I happened to know somebody who did crack cocaine, and I got addicted to it. When I found I was pregnant, I was so far into the addiction that it was hard for me to stop.

Sara did not discuss using alcohol or drugs, but she saw her overeating as a form of substance use, explaining:

I would say probably that's where my eating disorder is from [not working through the traumatic experiences]...And while I don't do drugs, I would say that my over-eating is probably the same thing underlying this drugseeking thing. As it happens, I can get my drug at McDonald's...

\section{High-risk behaviour, revictimization, and self-harm}

High-risk behaviour, including high-risk sexual behaviour, is an associated feature of PTSD for some people (APA 1994, Herman 1992). It can make sense as a coherent response to a variety of trauma-related experiences, emotions and sensations, including traumatic sexualization, low self-worth, numbness, being used to feeling fear, or having a foreshortened sense of one's personal future. Until her mid-20s, Ellen experienced some of those problems: 
I was still finding myself in bad situations with men, not knowing how to get out of it, not knowing how to have any control over the situation...I looked for sex...in order to get love...

Several participants had experienced sexual, physical, or emotional abuse and assault as adults, and they related their vulnerability to such revictimization to their experience of childhood abuse. Terry explained staying with an abusive partner this way:

So that's why I didn't just up and leave and walk away... because I was familiar [from childhood abuse] with that pain, of just staying there and allowing someone to treat me the way they wanted to treat me.

Self-harm and suicidality also are associated with severe past abuse and PTSD and co-morbid depression. Susan described fairly mild forms of self-harm, saying,

I just abuse myself. I pick at my skin, I bite my nails, I treat my body bad by not eating lunch and by drinking too much beer.

Pam had more acute urges to harm herself in labour, explaining:

What happened was that my labour became too painful to tolerate once I had gotten to about 6 or 7 centimeters. I was banging my head against a wall. I was starting to self-mutilate and was unable to cope...basically trying to create a counter-irritant, I think is what I was doing.

Julie did not disclose ever acting to harm herself, but she described a family history of depression and her own longstanding, pervasive depression with suicidal thoughts:

Depression runs in my family, so...I remember being...I'm not sure, I know that I was really little going on the [kindergarten school] bus feeling like I should be dead... and that is pretty bad for a five-yearold. What could be so bad, except for the sexual abuse? I just wonder if I didn't have an underlying chemical imbalance from the get go.

Pam disclosed acting on suicidal thoughts in the past and preparing to do so postpartum:

I was hospitalized briefly at one point for suicidal behavior. I have scars on my wrists from what was the last attempt at suicide, one that almost succeeded...I had piled postpartum depression on top of the pre-existing depression. I wasn't even an android. I was beyond that. On the way in [to a well-baby pediatrician visit] I had told my husband that I was going to kill myself and that I would give him a week to get his affairs in order before I did it.

\section{Conclusions}

In qualitative interviews carried out between nurses and 15 abuse survivors, women were able to identify aspects of abuse-related post-traumatic stress that affected their childbearing. They were able to describe their subjective experience of mental health and behavioural sequelae of childhood and adult abuse. They judged these post-traumatic stress manifestations to be problems that they needed to manage during pregnancy and for which they had some needs for help from maternity care professionals. Nurses, midwives, and physicians who are familiar with PTSD symptoms and associated features may be better able to assess trauma survivors' mental health status and determine their needs for trauma-related care.

\section{Limitations}

There are several limitations of this study due to the sample, narrative approach of the original study, and content analysis approach to the secondary analysis. The original study was conducted with 15 American participants and limited its focus to abuse-related post-traumatic stress. Also, half of the women had used psychotherapy as a healing modality prior to pregnancy, and most of the others did so subsequent to the birth. Therefore, the stories they told are specific to the American context and may also be specific to women inclined to seek professional mental health services for trauma-related distress or symptoms. Women from different cultures or societies, those who would not seek mental health services, and those whose post-traumatic stress results from qualitatively different trauma exposures (such as rape in the context of war, torture, or genocide) might differ in whether and how their post-traumatic stress manifests in pregnancy. The descriptions of PTSD core symptoms and associated features might differ in a different sample. Differences in descriptions from a different sample likely would enrich rather than invalidate the diagnostic conceptualization, because the existence of some form of post-traumatic stress has been validated repeatedly and affirmed in cross-cultural studies (Marsella et al. 1996, Wittchen 1994).

The narrative approach of the original study means that the interview text used in the secondary analysis takes the form of stories - childbearing narratives. The utterances extracted as part of the secondary content analysis are descriptions given in the service of telling that story. As such, they were not statements made for the purpose of providing detailed, comprehensive description of the lived experience of post-traumatic stress. A different approach and different interview procedures might have yielded more expansive descriptions.

The content analysis method intentionally compares qualitative text with existing theoretical frameworks and so does 


\section{What is already known about this topic}

- One in 10 women suffers from post-traumatic stress disorder in her lifetime.

- Post-traumatic stress disorder can complicate the experience of pregnancy.

- Maternity care providers often lack experience in recognizing post-traumatic stress disorder symptoms in childbearing women.

\section{What this paper adds}

- A framework for recognizing post-traumatic stress disorder core symptoms and associated features by linking women's descriptions of their symptoms with the formal diagnostic criteria.

- Recommendations for care during the childbearing year for women who have suffered from post-traumatic stress disorder.

- Recommendations for further research in this area.

not question whether the PTSD core symptom and associated features framework is the best possible way of understanding post-traumatic stress experienced by pregnant women. A grounded theory or phenomenological approach to both the interviews and the analysis might yield a different description or structure.

\section{Further research}

There is a need for further research on post-traumatic stress and childbearing. Diverse types of trauma exposures in international populations need to be examined for their salience to pregnant women. Diverse women, especially those for whom mental health professional services are not a primary healing modality, need to be studied. We need to know whether and how PTSD negatively affects maternal and infant outcomes across the childbearing year, and if women affected by PTSD have worse outcomes. We also need to test the effectiveness of PTSD-related interventions prior to or during the childbearing year.

\section{Clinical implications}

The descriptions these women gave in their interviews open to our view inner experiences that are consistent with the descriptions in the psychiatric literature of post-traumatic stress symptoms and associated features. The words they used to describe their subjective experience of post-traumatic stress manifestations sometimes do - but often do not include the professional language of the formal diagnostic taxonomy. Following-up routine screening questions about past and current abuse by asking about symptoms and associated features of post-traumatic stress using some lay terminology could offer an avenue for discussion with women who disclose an abuse history about how it is affecting them now. Self-report symptoms scales are also available to make assessment efficient and systematic (via the US National Center for PTSD at http://www.ncptsd.org/publications/ assessment). From there, maternity care professionals can collaborate with the woman to adapt prenatal care, labour, and postpartum follow-up to address trauma-related needs in an individualized manner, making referrals for mental health or maternal support services as desired by the client. More clinical research is needed so that we can move from tentative clinical conversations with individual women to researchbased understandings of the effects of post-traumatic stress on childbearing.

\section{Acknowledgements}

We express our appreciation to the 15 women who participated in this research. Thanks are also due to the University of Iowa College of Nursing Parent, Child, and Family Nursing Area of Study for the seed grant which funded the main study from which this report was derived, to Sherri Alms for editorial contributions, and to Carol Plummer, MSW, Julie Corkery, PhD, and Carolyn Zerbe Enns, PhD for being available to the participants for debriefing or referrals. This paper was completed while Dr Julia Seng was a Pfizer Postdoctoral Fellow and Dr Lisa Kane Low was a BIRWCH scholar at the University of Michigan.

\section{References}

American College of Obstetricians and Gynecologists (2001) Adult manifestations of childhood sexual abuse. ACOG educational bulletin, number 259. International Journal of Gynecology \& Obstetrics 74, 311-320.

American Psychiatric Association (2000) Diagnostic and Statistical Manual of Mental Disorders, 4th edn. Text revision. American Psychiatric Association, Washington, DC.

Berelson B. (1952) Content Analysis in Communication Research. Free Press, Glencoe, IL.

Bohn D.K. \& Holz K. (1996) Sequelae of abuse: health effects of childhood sexual abuse, domestic battering, and rape. Journal of Nurse Midwifery 41, 442-456.

Breslau N., Davis G.C., Peterson E.L. \& Schultz L. (1997) Psychiatric sequelae of post-traumatic stress disorder in women. Archives of General Psychiatry 54, 81-87. 
Eggly S. (2002) Physician-patient co-construction of illness narratives in medical interviews. Health Communication 14, 339-360.

Foa E.B., Keane T.M. \& Friedman M.J. (eds) (2000) Effective Treatments for Post-traumatic Stress Disorder: Practice Guidelines from the International Society for Traumatic Stress Studies. Guilford, New York.

Gazmararian J.A., Petersen R., Spitz A.M., Goodwin M.M., Saltzman L.E. \& Marks J.S. (2000) Violence and reproductive health: current knowledge and future research directions. Maternal Child Health Journal 4, 79-84.

Global Programme on Evidence for Health Policy (GPE/99.2). Putting Women First: Ethical and Safety Recommendations for Research on Domestic Violence Against Women. World Health Organization, Geneva, Switzerland. Accessed 14 October 2002 at http://www5.int/violence_injury_prevention/download.cfm?id=0000000130.

Heise L.L. (1994) Gender-based violence and women's reproductive health. International Journal of Gynecology and Obstetrics 46, 221-229.

Herman J.L. (1992) Trauma and Recovery: The Aftermath of Violence - from Domestic Abuse to Political Terror. Basic Books, New York.

Keirse M.J., Crowther C., Nelison J., Hodnett E., Hofmeyr J. \& Duley L. (2000) A Guide to Effective Care in Pregnancy and Childbirth, 3rd edn. Oxford University Press, Oxford.

Marsella A.J., Friedman M.J., Gerrity E.T. \& Scurfield R.M. (eds) (1996) Ethnocultural Aspects of Post-traumatic Stress Disorder: Issues, Research, and Clinical Applications. American Psychological Association, Washington, DC.

McFarlane J., Campbell J.C., Sharps P. \& Watson K. (2002) Abuse during pregnancy and femicide: urgent implications for women's health. Obstetrics and Gynecology 100, 27-36.

Miller D. \& Guidry L. (2001) Addictions and Trauma Recovery: Healing the Body, Mind \& Spirit. W.W. Norton, New York.

Morgan D.L. (1993) Qualitative content analysis: a guide to paths not taken. Qualitative Health Research 3, 112-121.

Parker B. \& Ulrich Y. (1990) A protocol of safety: research on abuse of women. Nursing Research 39, 248-250.

Petersen R., Gazmararian J.A., Spitz A.M., Rowley D.L., Goodwin M.M., Saltzman L.E. \& Marks J.S. (1997) Violence and adverse pregnancy outcomes: a review of the literature and directions for future research. American Journal of Preventive Medicine 13, 366-373.
Reissman C.K. (1993) Narrative Analysis. Sage, Newbury Park, CA.

Roth S., Newman E., Pelcovitz D., van der Kolk B. \& Mandel F.S. (1997) Complex PTSD in victims exposed to sexual and physical abuse: results from the DSM-IV Field Trial for Post-traumatic Stress Disorder. Journal of Traumatic Stress 10, 539-555.

Rothschild B. (2000) The Body Remembers: The Psychobiology of Trauma and Trauma Treatment. W.W. Norton \& Co., New York.

Seng J.S. (2002) A conceptual framework for research on lifetime violence, post-traumatic stress, and childbearing. Journal of Midwifery and Women's Health 47, 337-346.

Seng J.S. \& Hassinger J.A. (1998) Relationship strategies and interdisciplinary collaboration: improving maternity care with survivors of childhood sexual abuse. Journal of Nurse Midwifery 43, $287-$ 295.

Seng J.S., Oakley D.J., Sampselle C.M., Killion C., Graham-Bermann S. \& Liberzon I. (2001) Association of post-traumatic stress disorder with pregnancy complications. Obstetrics and Gynecology 97, 17-22.

Seng J.S., Sparbel K.J.H., Kane Low L. \& Killion C. (2002) Women's perspectives: abuse-related post-traumatic stress and desired maternity care practices. Journal of Midwifery and Women's Health 47, 360-370.

Simkin P. \& Ancheta R. (1999) The Labor Progress Handbook. Blackwell Science, Malden, MA.

Sironi F. (1999) Bourreaux et victimes: psychologie de la torture. Odile Jacob, Paris.

Stein M.B., Walker J.R., Hazen A.L. \& Forde D.R. (1997) Full and partial post-traumatic stress disorder: findings from a community survey. American Journal of Psychiatry 154, 1114-1119.

Tedeschi R.G., Park C.L. \& Calhoun L.G. (eds) (1998) PostTraumatic Growth: Positive Changes in the Aftermath of Crisis. Lawrence Erlbaum Associates, Mahwah, NJ.

Wittchen H.U. (1994) Reliability and validity of the WHO-Composite International Diagnostic Interview (CIDI): a critical review. Journal of Psychiatric Research 28, 57-84.

World Health Organization. (1978) International Classification of Diseases Manual of the International Statistical Classification of Diseases, Injuries, and Causes of Death. Based on the Recommendations of the Ninth Revision Conference, 1975, and adopted by the Twenty-ninth World Health Assembly. WHO, Geneva, Switzerland.

World Health Organization (2002) World Report on Violence and Health. WHO, Geneva, Switzerland. 